\title{
The imaginary worlds of sustainability: observations from an interactive art installation
}

\author{
$\underline{\text { Roy Bendor }}^{1}$, David Maggs $^{2}$, Rachel Peake, $^{\text {John Robinson }}{ }^{3}$ and Steve Williams $^{2}$
}

\begin{abstract}
We report on preliminary results from a public engagement project based on a procedural approach to sustainability. The project centered on an interactive art installation that comprised a live actor, an immersive soundscape featuring a handful of different characters, an interactive touch-table, and four interactive rooms within which participants wandered, partially guided by a narrative through-line, yet at the same time left to make sense of any larger meanings on their own. The installation was designed to experiment with two propositions: (1) that there is value in public engagement with sustainability based on the exploration and articulation of deeply held beliefs about the world - the worldviews, values, and presuppositions that mediate perception and action; (2) that there is value in replacing the infocentric tendency of most public engagement on sustainability with an approach premised in aesthetics and experiential resonance. Following the installation's two-week pilot run, our preliminary results indicated that the majority of participants found the experience both resonant and thought provoking, and were mostly willing to critically engage with their preexisting notions of sustainability.
\end{abstract}

Key Words: art; cultural dimensions of sustainability; imagination; ontological agency; social constructivism

\section{INTRODUCTION}

Historically speaking, the challenge of sustainability has been viewed as one of proving the world real. Scientific warnings about the hard reality of environmental limits, from the Limits to Growth report (Meadows et al. 1972) to contemporary work on planetary boundaries (Rockström and Klum 2015), provided the factual basis for both public engagement campaigns and relevant policy making. Yet despite success with tractable environmental issues such as acid rain and the hole in the ozone layer, this approach is proving far less successful with complex challenges or "wicked problems," such as climate change, where not only do multiple biotic factors interact strongly with sociocultural and political systems, but the very definition of the problem itself is contested (Rittel and Webber 1973). What if the challenge of sustainability is not to prove the world more real but to prove it more imaginary? (Maggs and Robinson 2016). This provocation provides the impetus for the project on which we report here.

Our project embodies a commitment to "procedural sustainability" (Robinson 2004), according to which "sustainability can usefully be thought of ... as the emergent property of a conversation about desired futures that is informed by some understanding of the ecological, social and economic consequences of different courses of action" (Robinson and Cole 2015:137). We understand sustainability as an essentially contested concept, like truth or justice (Jacobs 2006, Connelly 2007, Ehrenfeld 2008), not a "universalist" end-state shaped by the value-free dictates of scientific descriptions, but the dynamic, fluid outcome of processes of negotiations among interested parties about what kind of world we want to live in (Miller 2013). Such a view places emphasis on the imagination because sustainability can no longer rely exclusively on scientific knowledge production to determine the right path to a single sustainable future. Rather it relies on how well society explores, imaginatively inhabits, and evaluates multiple possible futures; on the kind of stories societies tell about who they are and what is important to them; and on the avenues for collective action that open up as consequence. This view also implies a significant, ontological shift: instead of a world made of objects whose reality can be established in absolute terms, we must contend with dynamic and contingent cultural forms that shape the ways such facts are constituted, expressed, and interpreted (Watzlawick 1977, Goodman 1978, Berger and Luckmann 1989, Latour 2004).

Accordingly, our goal was to experiment with an approach to public engagement on sustainability that shifts away from making people face some brute reality, away from "a single slow-moving disaster scenario"(Moffat 2014:202) and toward enchanting them with the openness of the world as an imaginary place. We aimed to do so by combining two fields of sustainability engagement: scenario analysis and the arts, both of which have much to offer, and gain from, such a transition. In particular, we wanted to combine the openness to multiple possible futures of scenario analysis and the playfulness and imaginative enchantment of art to explore futures that reflect the "worldmaking" (Goodman 1978, Vervoort et al. 2015) potential of sustainability and its dependence on underlying ontological assumptions about the world. Working from the procedural approach to sustainability, the project seeks to explore two propositions: one related to the way sustainability is understood, the other with the way it may be communicated.

The first proposition centered on engaging sustainability through an exploration and articulation of deeply held beliefs about the world-the worldviews and presuppositions that mediate society's perception of and action in the world, or what Charles Taylor (2004) calls the "social imaginary." If the public's perception of, and, consequently, ability to act on sustainability is always already premised in these prior, often axiomatic, ontological dimensions (or "worlds"), would rendering these worlds explicit and therefore available for reflection lead to new understandings of sustainability? And could fostering a plurality of interpretations of sustainability generate new ways to engage with it?

The second proposition focused on replacing the infocentric tendency that underlies most public engagement on sustainability with an approach premised in aesthetics and experiential 
Table 1. Main characteristics of the three worlds.

\begin{tabular}{|c|c|c|c|c|c|c|}
\hline World & Voice & Mandate & Room & Ritual & Tree & Leaf \\
\hline Spiritual & Sarah & $\begin{array}{l}\text { Connect to higher } \\
\text { power }\end{array}$ & $\begin{array}{l}\text { White, plain, calming, } \\
\text { barren }\end{array}$ & $\begin{array}{l}\text { Put on a mask, walk the path } \\
\text { around the tree }\end{array}$ & $\begin{array}{l}\text { White, one growing up from } \\
\text { ground, one hanging down } \\
\text { from ceiling }\end{array}$ & White \\
\hline Materialist & Matt & $\begin{array}{l}\text { Figure out how } \\
\text { things work }\end{array}$ & $\begin{array}{l}\text { Copper, mechanistic, } \\
\text { interactive }\end{array}$ & $\begin{array}{l}\text { Unlock locks, make the tree } \\
\text { bloom }\end{array}$ & $\begin{array}{l}\text { Copper, with locks, cables, } \\
\text { pulleys, etc. }\end{array}$ & Copper \\
\hline Literary & Lauren & Create new stories & $\begin{array}{l}\text { Green, nostalgic, } \\
\text { mysterious, interactive }\end{array}$ & $\begin{array}{l}\text { Open the doors, experience } \\
\text { one's self reflected through } \\
\text { various filters (mirrors, } \\
\text { screens, etc.) }\end{array}$ & $\begin{array}{l}\text { Driftwood, one tree } \\
\text { segmented into jars, the } \\
\text { other has jars hanging from } \\
\text { its branches }\end{array}$ & Green \\
\hline
\end{tabular}

resonance. Guided by recent research that demonstrates the limitations of engaging the public strictly based on information and knowledge transfer (Green and Kreuter 2005, Jackson 2005, Steg and Vlek 2009, Shove 2010, McKenzie-Mohr 2011), we sought to use narrative, characters, sensorial triggers, and emotional messaging to stir something new with participants. Would evoking meaningful experiences prompt participants to consider sustainability in new and powerful ways, to move beyond thinking about the facts of sustainability to contemplating the concerns it raises? In this, the project joins others who have advocated for a greater role for the arts, humanities, and interpretive social sciences in promoting social engagement with sustainability, climate change, and other "wicked" problems (Hulme 2009, Yusoff and Gabrys 2011, Castree et al. 2014, Garrard et al. 2014, Lövbrand et al. 2015).

The vehicle we designed to explore these questions took a hybrid form, part immersive theatre, part interactive installation. The experience comprised a live actor, an immersive soundscape featuring three different characters, an interactive touch-table, and three interactive rooms within which participants wandered, partially guided by a narrative or storyline, yet at the same time left to make sense of any larger meanings on their own. The installation was the centerpiece of our project, Sustainability in an Imaginary World, which began its development in the spring of 2014. During the initial year of the project, the conceptual framework, research strategy, and preliminary design approach were developed. A core design team was in place by the spring of 2015, with the full production team working through the fall of 2015. The first public previews, on which we report here, took place in January 2016. During that period the installation sold out its entire run of 40 performances over 2 weeks. A total of 172 participants took part in these initial runs. They were invited to complete a pre-experience survey that, as will be described below, was scripted as part of the installation's narrative. After exiting the installation participants had the opportunity to complete a postexperience survey and to participate in a 30-minute followup group discussion. The results of the two surveys and group discussions form the basis of the findings outlined in this paper, which, in turn, informed the installation's redesign and remounting during January and February 2017.

\section{DESIGN}

\section{Ideation and creation}

As a way to tease out those deeply held beliefs about the world, the installation's form and content centered on an encounter with different "worlds," each one representing a fundamentally incommensurable axiomatic belief about the nature of reality. Taking inspiration from American philosopher Richard Rorty (2007), we articulated three prototypical worlds: spiritual, materialist, and literary. The respective axioms that underlie our interpretation of these three worlds can be summed up as follows: a spiritual world rooted in truth transcendent of natural or social reality but approachable through faith in a higher power or a divine plan; a materialist world rooted in truth immanent in nature and natural laws and discernible through experimental (scientific) inquiry; and, last, a literary world resting on multiple truths, mutable and layered, at once historical and intersubjective. Fostering encounters with these worlds as varying contexts within which to consider sustainability became the focus of the installation and informed many of its features (see Table 1; we give a more detailed description of the design in Bendor et al. 2015).

In terms of form, the intersection between the expressive vocabularies of art and the choice making that is central to scenario analysis landed the design squarely in the realm of interactivity. The result was an immersive theatre piece that included characters and storyline, fully designed and constructed theatrical sets, and a live actor, but that also experimented with a "responsive aesthetic" (Krueger 2003) in the form of locationbased audio content delivery, a touch-table, and several digital and analog interactive technologies such as real-time video feeds and puzzles. This hybrid environment, which we describe in more detail below, was an attempt to capture and balance the enchanting engagement of an experience sculpted according to a controlled aesthetic vision, with the engagement that comes out of audience participation and interaction. The experience lasted approximately 50 minutes and comprised five "scenes" followed by a debriefing component which, we discovered, became crucial to the experience.

\section{Open-endedness as a design feature}

When we first set out to design the installation we entertained the notion of the labyrinth as a psycho-spatial metaphor for the kind of experience we wanted to evoke. This was based on a homology between our approach to sustainability and the installation's form. An important motivation for the project was our belief that sustainability has been long approached as a singular endeavor, one that typically foregrounds scientific understanding as the only source of valid knowledge, not just about what sustainability is and means, but about how it should be addressed in practice. Our own approach, based on the procedural approach to 
sustainability, foregrounds the view that the nature of sustainability itself is open for discussion and can be expressed in fundamentally different ways. Accordingly, we sought to embed our approach to sustainability in the very structure of the installation. If sustainability was open-ended, fraught with uncertainty and indicative of a multiplicity of possibilities, so too would be the kind of experiences we wanted to evoke in participants.

The homology between sustainability and the installation operated on both spatial and hermeneutic levels: spatially, we wanted to keep the movement within the installation as free as possible, inviting wandering, playfulness, and reflection instead of nudging participants to follow a particular, predetermined sequence of actions. With that said, time and narrative constraints meant that the installation would inevitably include stages where participants had to follow a particular trajectory, resulting in the installation being less labyrinthine than we hoped, with freeform wandering largely restricted to scenes 2 and 4 (see below). Hermeneutically, we wanted to keep the installation as open to interpretation as possible. Our use of more abstract, ambiguous, and nuanced symbolism was designed to evoke reflection without narrowing down participant interpretive strategies, electing to promote ambiguous instead of persuasive messages. In other words, we tried to open up the experience to a variety of interpretative strategies instead of narrowing the latter to the ones we deemed most appropriate.

\section{Narrative}

Although the installation was designed with as much spatial and interpretive open-endedness as possible, we did not want to leave participants too perplexed or baffled. Neither were we interested in creating a "choose your own adventure" kind of narrative. The framing of the experience with a fixed narrative, therefore, helped to establish a form of continuity throughout the installation's otherwise discontinuous spaces, but also to draw a contrast between the more and less familiar aspects of the experience. So on the one hand, the narrative helped to keep the experience's timing and rhythm under control, an important task given the way participants were organized as groups and led into the installation (see below). On the other hand, the narrative helped to establish what we thought would be productive contrasts in both form and content. In terms of form, because the experience starts and ends with the narrative, while in between participants undergo a much more abstract experience, the narrative maintains a contrast between attentiveness and activity. When engaged with the narrative participants are attentive spectators. When leaving the narrative behind participants become actively engaged with the installation's interactive features. The narrative functions similarly in terms of content, helping to create a thematic contrast between more and less standard ways to understand and communicate sustainability. Although much of the experience sought to establish new, unfamiliar frames of interpretation, the narrative was a well-known scenario: a state of emergency triggered by impending catastrophe.

\section{THE INSTALLATION}

\section{Scene 1}

Arriving at the box office, participants were greeted by an officious host, who handed them headsets connected to an iPad (in a pouch to be slung over the shoulder and ignored). They were ushered into a registration room consisting of tables with separate iPads and a large television. They were asked to complete a survey on the iPads collecting genuine research data (demographics, attitudes toward sustainability, and so forth). The survey then began to ask peculiar questions, probing their tolerance for various levels of eco-fascism. This was followed by a video telling them of a mysterious glowing object found offshore that seemed to provoke the standard narrative of climate doom, natural disasters, social unrest, political collapse, along with the urgent necessity of the Integrated Policy Response Commission (IPRC) to re-establish order and control. Just as the video ended, a janitor (actor) snuck into the registration room and told the participants he did not believe all this panic and urgency. "Something else is going on," he said. Before accepting the IPRC demands he insisted they come explore a strange room (see Fig. 1).

Fig. 1. The janitor whisks participants into the "secret" room. (Photo by Emily Cooper.)

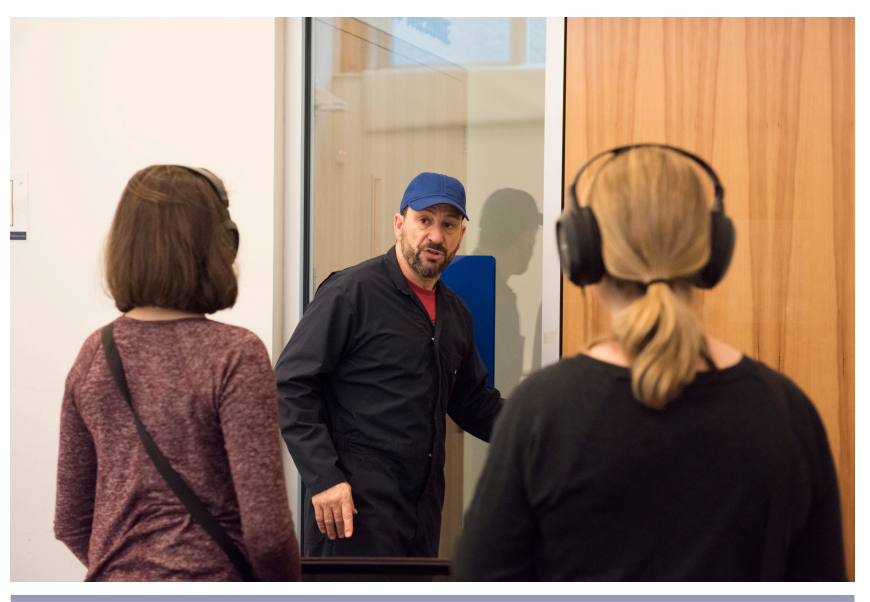

Scene 2

Our janitor ushered participants into an industrial space and left them there to explore on their own. Crates were strewn around the room, 30-foot tarpaulin sheets hung from the ceilings, with low light and industrial hum completing the mood. Eventually three different voices were heard in participants' headsets, describing the unusual climate event that had sparked this panic. They each offered a solution drawn from three very different worldviews (reflecting the three axiomatic worlds described above). Suddenly, IPRC forces were banging at the doors declaring the participants' presence unauthorized, but the doors had mysteriously locked. As the surface of a centrally located crate lit up to reveal itself as a touch-table, a computer voice (distinct from the three characters) beckoned participants to approach it.

\section{Scene 3}

Huddled around the touch-table participants were asked, as a group, to make two choices as to how best to address this crisis: the first was a choice between solutions based primarily on technological innovation and those that require significant changes in human behavior and lifestyle (Fig. 2). The second posed a trade-off between collective responses and those based 
on individual action. Individual choices made by participants were then aggregated and combined into one of four possible solutions: individual/lifestyle (driven primarily by changes in individual choices about consumption behavior); collective/ lifestyle (changes to collective consumption patterns that would be enacted through top-down policy changes); individual/ technological (individual choices would occur mainly through the development of new technology); collective/technological (government or corporatist policies would lead to significant technological change). After the group completed its selection, the touch-table revealed an image that illustrated symbolically the world the group's choice implied. The same image was then modulated and projected in the three rooms discussed next.

Fig. 2. Group decision making around the touch-table. (Photo by Emily Cooper.)

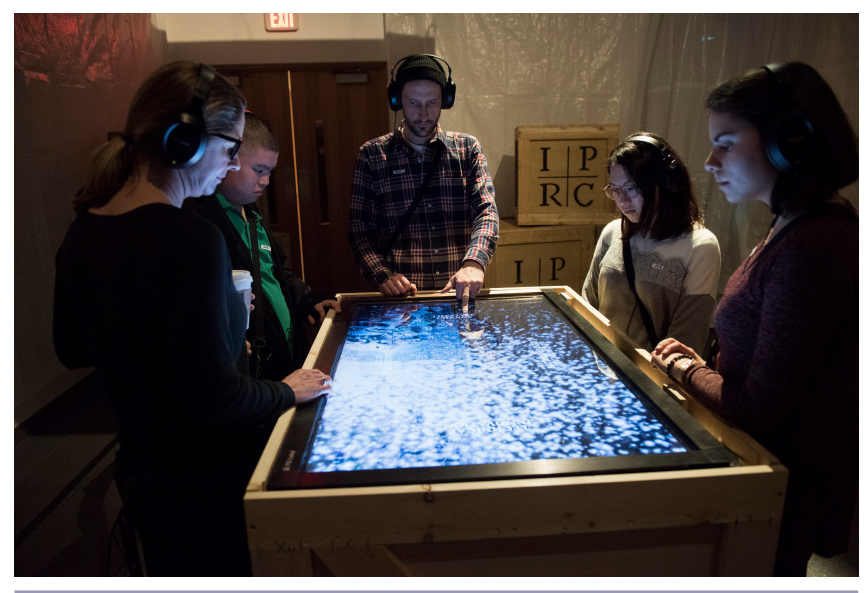

Scene 4

As the image that resulted from the group's choices faded on the surface of the touch-table, three doors lit up on the perimeter of the industrial room (see Fig. 3). There were no additional cues or instructions for participants, who may or may not enter the rooms, and may do so in whatever sequence they desired. These doors led to three different rooms, corresponding to the three worldviews participants had been hearing about in their headsets: a spiritual room, a materialist room, and a literary room. Inside each room, we heard one of the three voices from earlier on, further exploring their worldview and their preferred way of addressing the looming crisis. Each room contained a representation of a tree and various interactive affordances designed to manifest that worldview (see Table 1). Each room was also covered in leaves of a particular color that matched that room. For the spiritual room, white wood paneling and a worn path encircled a white tree growing up from the centre of the room, meeting the branches of a white tree hanging down from the ceiling (see Fig. 4). Two masks hung on the wall, available to be worn in a slow ritual of contemplation. For the mechanistic room, copper walls and steampunk aesthetic housed a metallic tree adorned with locks, keys, chains, and pulleys that released blossoms when linked together (see Fig. 5). For the literary room, nine doors opened to reveal various contemplations on self and world including a tree sectioned inside stacked jars, jars hanging from another tree, two fun-house mirrors, several screens that displayed a distorted live camera feed, curiosity shelves, and a door that did not open at all (see Fig. 6). The experiences inside these different rooms were loosely structured by audio and lighting cues, gently guiding (but not forcing) movement from one room to the next. Interrupting these punctuated experiences in the different rooms were the panicked shouts of the IPRC demanding that participants take the crisis seriously and do as they say.

Fig. 3. Main gallery after the appearance of light cues for the three rooms. (Photo by Emily Cooper.)

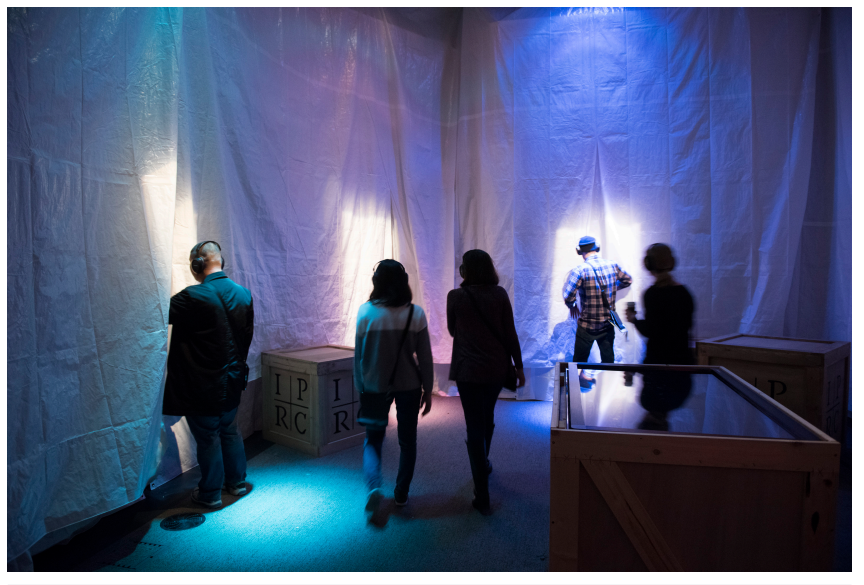

Fig. 4. The spiritual room. (Photo by Emily Cooper.)

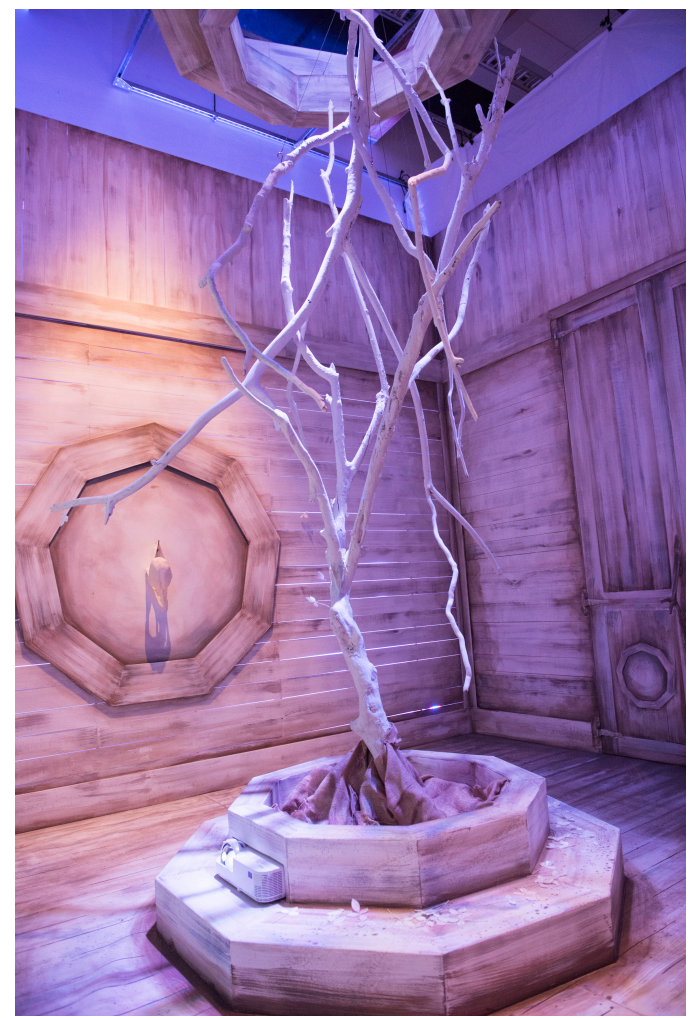


Fig. 5. The materialist room. (Photo by Emily Cooper.)

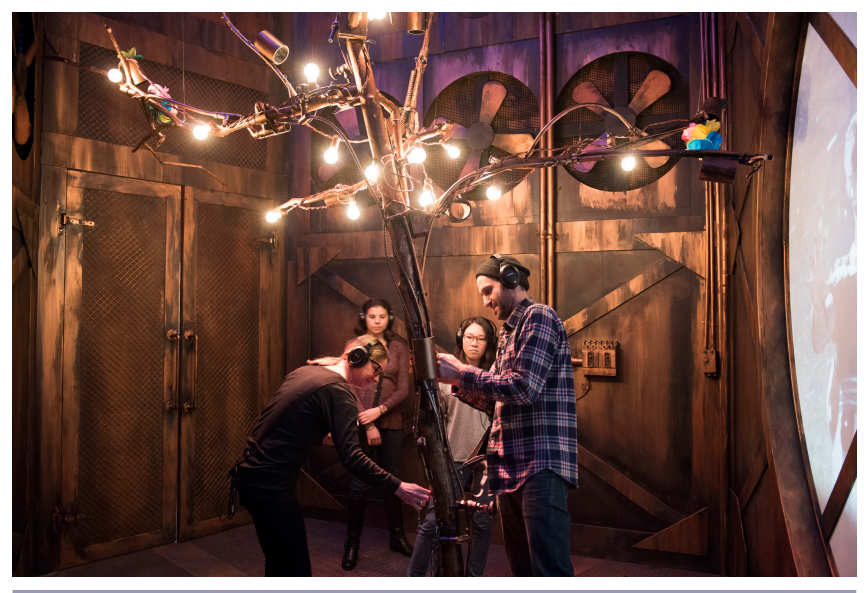

Fig. 6. The literary room. (Photo by Emily Cooper.)

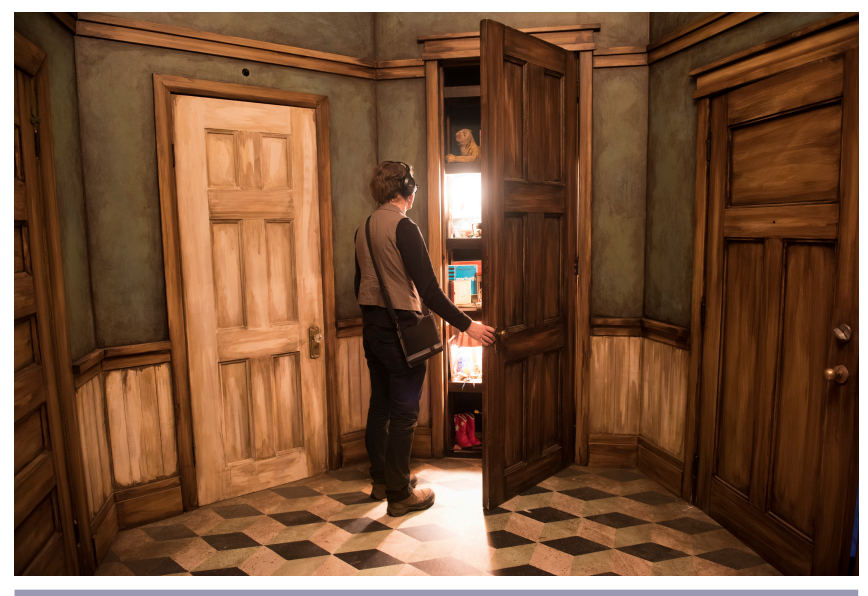

Scene 5

After the third room had been visited and the cries of the IPRC had grown more desperate, participants heard a door open in the outer space. As harsh fluorescent lights snapped on, the janitor called out, "folks, I'm sorry. I should never have let you in here." The janitor implored participants to do as the IPRC says and come with him. He collected the headsets, put them in a bin, and led everyone out of the room. But just as they were about to depart, the lights dropped again, and a crate hanging overhead opened up to reveal a glowing object inside. The computer voice called out for participants to wait because there was one choice left to make. A wooden surface (part of the hanging crate) descended bearing a multitude of leaves color-matched to the leaves and colors of each of the three rooms that were just experienced (see Fig. 7). Participants were then invited to choose a leaf that represented what they thought would prove the most promising orientation to the problem at hand: "White leaves for the knowledge that something is out there. Copper leaves for the faith that answers will come. Green leaves for the comfort in knowing no world is carved in stone." Each time a leaf was plucked, a representation of the tree from the corresponding room (white, metallic, and the one with jars) appeared on the walls, ultimately reforesting the industrial space in a way that showed participants how many in their group made each choice. Participants were then ushered to a separate room where they were invited to complete a postexperience survey and take part in a group discussion about the experience and its meaning.

Fig. 7. Leaf selection. (Photo by Emily Cooper.)

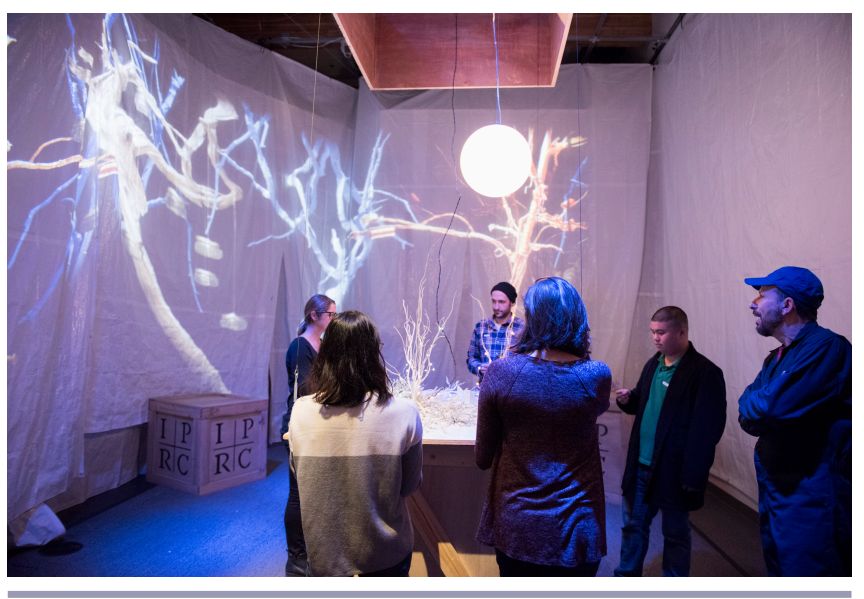

\section{PRELIMINARY EVALUATION}

\section{Research design}

Our research design consisted of three interrelated activities. First, we accompanied and observed several of the groups as they went through the installation. This allowed us to witness first hand participant responses to audio and visual cues, trace the ways in which groups navigated the installation's spatial structure, and identify group dynamics that may influence the experience. Second, we conducted pre-experience and postexperience surveys with participants, resulting in 139 complete responses (with additional 33 responses to pre-experience survey only). This gave us a sense of participant demographics, their previous involvement with sustainability, and their predispositions vis-àvis the typology of worlds presented in the installation (see Table 1 and Scene 4 above). These could be later compared to choices made within the installation, allowing us to start assessing the installation's impact in terms of participants' views on sustainability and attitudes toward the future. Last, we conducted group discussions with roughly half of all groups immediately following their exit from the installation. This gave us the opportunity to ask more critical questions about the kind of experiences participants had, and about the effectiveness of different installation features. It also gave us an initial sense of the kind of interpretative strategies enacted by participants when encountering the installation's fairly open-ended structure.

It soon became clear that these discussions themselves became part of the experience, actively shaping participant impressions and thoughts on what they went through. In one memorable discussion, after exiting the installation the three participants had very strong negative comments, but during the group discussion changed their views entirely! In light of this and other instances, we came to see participant accounts during group discussions not 
as reflections on an autonomous, compartmentalized experience but part and parcel of that very experience. And while, on the one hand, this means that the group discussion data may be "contaminated" by our presence, we consider it a worthwhile trade-off because group conversations yielded interesting insights and participants expressed their appreciation of the opportunity to reflect on the experience with others.

\section{The meaning(s) of sustainability}

As mentioned above, the first proposition underlying the project is that the ways in which we perceive, give meaning, and act on sustainability are premised in deeper cognitive, cultural, and ontological structures. How we understand sustainability, it follows, is inherently tied to how we understand the world, ourselves, and others, and to the ways in which we render those beliefs actionable. In this sense, the project seeks a new foundation for public engagement with sustainability that makes explicit the relations between the ontological (how we understand the nature of the world) and the ethical (how we believe we should act on it). This relation was pursued through a set of theatrical, interactive features that were intended to destabilize singular understandings of sustainability, what we largely identify with a "universalist" view of sustainability (Miller 2013) as a matter of science-based, complex problem solving. To be clear, we did not aim to teach participants something new about sustainability or to persuade them that this view or another was preferable. What we sought was to destabilize any singular meaning of sustainability by evoking a greater awareness of the relationship between different worldviews and different conceptions of what sustainability means.

We were partially successful in achieving this goal. On the one hand the majority of participants reported in surveys that their views on sustainability have not changed following their visit to the installation. On the other hand, in group discussions that took place after postexperience surveys were completed we noticed that quite a few participants were not only willing to reconsider critically the kind of meanings they attributed to sustainability, but were also willing to concede that other meanings were as valuable. In some cases this was expressed in moments of reflexivity where participants remarked that they have indeed changed their mind, while in other cases such shifts were subtler. Some participants insisted that their views had not changed while at the same time expressing different views than the ones they had expressed before! And in some cases participants had already expressed views that were roughly equivalent to the kind of pluralization we sought, and their views did not change at all.

Based on the surveys and interviews we conducted, we believe several elements mediated the installation's capacity to evoke a plurality of interpretations of sustainability. First, technical difficulties, especially in terms of weaving the various aspects of the three worlds throughout the installation (see Table 1), have concealed some of the nuanced ways in which we sought to relate the three worlds to the larger context. If the three worlds could not be related to the enveloping narrative, the ontological layer remained somewhat disconnected from the rest of the experience. And if the decision-making components (the touch-table and leaf selection) would not function properly (and at times they did not), the agentic dimension remained unconsummated. In this context, some of the audio issues that interfered with the process of leaf selection worked against the possibility of gaining a more robust knowledge about participant preference of worlds, and therefore reduced our capacity to evaluate the degree to which participants may have indeed shifted their views (their initial position was evaluated in the pre-experience survey).

Second, the installation attracted participants with strong preexisting views on sustainability. Its physical location in the Centre for Interactive Research on Sustainability (CIRS) building on The University of British Columbia's main campus, and the fact that much of the installation's promotion targeted the university's sustainability community, meant that participants were not statistically or otherwise representative of the general public, were relatively well educated $(35.5 \%$ reported that they attained a postgraduate degree in comparison with $6.5 \%$, which is the Canadian national rate), and were already sensitive to, interested in, and active on issues related to sustainability. Indeed, more than half of the participants stated that they were "very active" on sustainability issues, with an additional $30 \%$ stating that they were active on sustainability issues "more or less the same as others" (see Fig. 8).

Fig. 8. Participant responses to the question, "How active are you on matters related to sustainability?"

\begin{tabular}{|c|c|}
\hline Response & Count \\
\hline Never heard of it & $1(0.6 \%)$ \\
\hline $\begin{array}{l}\text { I am aware of it, but } \\
\text { not active on } \\
\text { matters related to it }\end{array}$ & $29(16.9 \%)$ \\
\hline $\begin{array}{l}\text { I am active more or } \\
\text { less the same as } \\
\text { others }\end{array}$ & $52(30.2 \%)$ \\
\hline I am very active & $90(52.3 \%)$ \\
\hline & Total: 172 \\
\hline
\end{tabular}

Despite these difficulties, a more detailed look at participant responses reveals some interesting patterns. For instance, several participants associated sustainability with care for nature, the urgent need for lifestyle changes, or concern for future generations. As one anonymous participant put it,

\section{Sustainability is loving Mother Earth and not taking more than we can give. And making sure not to use up resources. It's a balance. It's eating local, it's rotating crops, it's a whole bunch of things. And it's a whole bunch of things that takes a lot of people. (All italicized citations are transcribed from postexperience group discussions.)}

In addition, many participants identified sustainability with systemic change. For example, one participant told us that,
I think when it comes to sustainability it's to create a system. An effective system that can basically last forever. But one of the caveats with that is that we can constantly change the system to our liking.

Although these views appear to represent the popular, mainstream approach to sustainability, when we asked participants in the postexperience survey about their perception of sustainability, the majority "agreed" (38.7\%) and "strongly agreed" (32.4\%) that "achieving a sustainable future goes beyond decisions about specific technologies, behaviours or policies," a position that seems to reflect more of a "procedural" then a 
"universalist" (or science-centric) view of sustainability (Miller 2013). We heard similar opinions from participants in group discussions:

\begin{abstract}
It's not all about what's on the outside, or at the top.... it really expressed that it's multiple scales, inside of you and outside of you ...
\end{abstract}

Technology will not get us out of this situation. I think it will probably help, but it's not [going to be the solution].

I felt like it was the stuff behind sustainability and more the social aspects of sustainability which are often the last parts that we are just starting to get to.

People always talk about sustainability but then how do we reach our goals? How do we do that? There isn't one answer

This leads us to believe that although most participants reported that their views on sustainability have not changed following their experience (see Fig. 9), they were less secure in their previous positions. As we further discuss below, we suspect this discrepancy has much to do with the relations between participant expectations and the installation's actual features.

Fig. 9. Participant responses to the statement, "After visiting the installation I feel my views on sustainability have changed."

\begin{tabular}{ll} 
Response & Count \\
\hline Strongly disagree & $33(23.7 \%)$ \\
\hline Disagree & $41(29.5 \%)$ \\
\hline Not sure & $40(28.8 \%)$ \\
\hline Agree & $20(14.4 \%)$ \\
\hline Strongly agree & $5(3.6 \%)$ \\
\hline & Total: 139 \\
\hline
\end{tabular}

\section{Aesthetics over information}

The second proposition that guided the installation's design was that it is possible to engage the public on sustainability not through an infocentric prism but from the perspective of aesthetics and experience. We were not interested in informing or educating but in provoking: instead of providing participants with relevant, salient, and actionable information about sustainability, or trying to educate them about the kind of problems and solutions associated with it (and which often tend to be articulated through a science-centric approach), we wanted to create an emotionally stirring, resonant yet thought-provoking experience. Importantly, we wanted to create an experience that would stand up to artistic standards, that is, could be appreciated and even enjoyed for both its content and its form.

Indeed, a large majority of participants responded to the experience positively. Over $46 \%$ of participants said they "enjoyed" the experience as a whole, while $34.3 \%$ said they "enjoyed it a lot" (see Fig. 10).

Furthermore, nearly $30 \%$ of participants said they intend to visit the installation again, with an additional $48.3 \%$ saying that they "may" return. Last, nearly $72 \%$ of participants said they would recommend the experience to their friends. This was further confirmed in group discussions when several participants told us that their visit to the installation was prompted by lively conversations with others who had already visited. These findings helped alleviate some of our deepest concerns about the installation's capacity to create an experience that would be both aesthetically appealing and capable of generating insights about art-based public engagement in general terms.

Fig. 10. Overall satisfaction with the experience.

\begin{tabular}{ll} 
Response & Count \\
\hline Didn't enjoy it at all & $1(0.7 \%)$ \\
\hline Didn't enjoy it that much & $9(6.4 \%)$ \\
\hline So-so & $17(12.1 \%)$ \\
\hline Enjoyed it & $65(46.4 \%)$ \\
\hline Enjoyed it a lot & $48(34.4 \%)$ \\
\hline & Total : 140
\end{tabular}

In group discussion participants reported high levels of excitement and emotional or affective engagement with the installation:

It felt like I was in a movie or an adventure movie and it was really surreal. Yes, you feel like you're in your imagination like the title of this installation but you really feel that.

Some participants even reported being shaken by the experience:

It felt very frantic. Not frantic but just a bit weird and there's moments when it's dark and you hear voices in your head and it's a little freaky and you're opening a door wondering what's going to be there, something's going to pop out.

\section{I mean the whole exhibit upset me.}

This was confirmed in surveys. We used a modified version of the PANAS scale (Watson et al. 1988) that included 4 positive and 4 negative values on a 5-point Likert scale, to evaluate participants' affective responses to the installation. We found that reports of positive affective experiences roughly doubled negative ones, that is, the installation generated twice as many positive emotional experiences than negative ones. In particular, participants reported high and very high levels of positive affective responses such as interest (high: $53.8 \%$; very high: $31.8 \%$ ), excitement (high: 50.7\%; very high: $9.7 \%$ ), enthusiasm (high: $32.9 \%$; very high: 11.9\%), and feeling inspired (high: $27.7 \%$; very high: $9.9 \%$ ). Consistent with this, participants reported low and very low levels of negative affective responses including distress (low: $34.3 \%$; very low 26.6\%), being upset (low: 19.6\%; very low: $56.6 \%$ ), feeling guilty (low: $32.2 \%$; very low: $51 \%$ ), and feeling scared (low: $24.6 \%$; very low: $36.6 \%$ ). Perhaps our most interesting finding in this respect, was the existence of a moderate (borderline strong) correlation $(r=+0.49)$ between the overall degree of combined positive and negative affective resonance reported by participants and the extent to which they were satisfied with the experience as a whole. In this sense, high negative affect can be seen as equally beneficial for effective messaging as high positive affect (consistent with the findings of Hine et al. 2016).

Although participants reported that they liked the kind of reflexive emotional tonality evoked by the installation, they also told us that they wanted more interaction: more group collaboration, more tasks or puzzles to solve, and more opportunities to shape what takes place within the installation. 
We are still unsure whether this is because of the way the installation was framed (the narrative and video introduction in particular), or whether this may be an outcome of the mental model of sustainability carried by participants (as noted above). Participants who understood sustainability as predominantly a question of collaborative, complex decision-making may have expected the installation to serve as a platform for that. A third possibility is that participants may have had trouble adjusting their expectations to the mixed vernacular the installation used, so the combination of the more passive or spectatorial theatrical elements and interactive affordances may have left participants confused about the degree to which they were to be active. These types of comments, again, point toward the importance of considering more carefully participant expectations, or more accurately, the dynamic relations between expectations and actual affordances (or features).

We encounter a similar issue when evaluating the installation's open-endedness. Some, but not all participants embraced the installation's ambiguity and relished the interpretive freedom it offered. In the context of spatial open-endedness, and through both observation and survey responses, it became clear that participants indeed moved between the installation's three rooms freely. Rooms were visited in random order (with more or less equal distribution of room sequence). Some groups moved through the rooms together, while others did not. One group did not go into the three rooms at all, and one group was so inquisitive that it found the rooms before the visual cues were given and therefore explored the rooms out of sync with the audio-based narrative. They told us the following:

We were looking around the room. We were pushing the
table top, and nothing came on. We were touching the
screen, the big screen. And then there were all of these
stories, and then we started exploring the room. So I
started looking behind the white stuff, the white drapes,
to see if there was any other part of the installation ... it
was just the two of us, and we were both banging on boxes
and trying to open the boxes. I started exploring behind
the white drapery, and I found the first door. That was cool.

To be clear, we do not see such freeform movement as a failure of our designerly intentions but as reassuring manifestations of the openness we sought. Veering off script, insofar as one existed, was welcome, not resented.

Cognitively speaking, in group conversations participants said that they recognized and appreciated the installation's interpretative openness, as evident, for instance, in the way participants perceive the same design features in quite diverse, and at time even contradictory ways. Although the spiritual room, for instance, evoked a sense of peacefulness and reflection for some, others described it as a bleached out, empty space conveying the distinct sensation of a postapocalyptic nightmare. The materialist room was largely seen as a container of puzzles or mysteries to solve. But it was also seen to be overly artificial, cold, and unrewarding, especially to those participants who were unable to detect the flowering caused by manipulating the locks and pulleys. Last, the literary room was liked for the freedom of exploration it offered, the sense of wonderment and nostalgia it evoked, and the playfulness it offered. But at the same time, participants also reported being frightened by the unknown things that awaited them behind the closed doors, being frustrated by finding one of the doors locked (especially if they visited the mechanistic room previously and thus were expecting solvable puzzles), and the sadness they felt precisely because of the same air of nostalgia others appreciated.

Nevertheless, providing participants with a looser, more openended structure was not without risk. First, problems with audio legibility in the final act of choice-making (Scene 5) resulted in palpable anxiety over the question of whether participants did what they were "supposed to." Although some of the instructions given to participants either lacked clarity, or were marred by technical difficulties, the larger issue here is the question of guidance: although participants enjoyed the freedom to move and interpret the installation as they pleased, some were also craving more guidance. Take for instance the following:

\section{I guess after realizing that nothing was going to happen in real time, that I just realized it's just a place that you explore. So I'll keep exploring. But then it became a waiting game just waiting for something to happen.... there was nothing of consequence.}

We recognize that some of these difficulties resulted from technical breakdowns, but we cautiously believe that this can also be seen as evidence of the kind of challenges that are inherent to designing labyrinthine structures in general, that is, pitching them at the right scale as to inspire a sense of freedom and agency while avoiding creating too much anxiety, bafflement, or boredom.

Second, a significant group of participants expressed their desire to have had more time to wander in the installation, digest its sensorial provocations, and reflect upon its themes and symbolism. Several participants complained about the ratio of auditory vs. visual content, reported sensorial overload, and felt so much palpable stress as result of the experience that they seemed in need of support and reassurance. At the same time, and as mentioned above, the correlation between reported degrees of affect and overall appreciation of the experience leads us to believe that even those who have had a more stressful experience found it rewarding. This, in turn, indicates that producing a resonant experience should not be seen as equivalent to producing a positive emotional experience. There is much to be said about the benefits of evoking unpleasing experiences or "complicated pleasures" (Dunne and Raby 2001) as a way to trigger deeper reflection; we certainly feel that the installation managed to provoke reflections about sustainability by creating unordinary experiences. It is also worth noting that participant experiences may seem quite different in retrospective, something we aim to address by asking participants to revisit their experience of the installation over the next few months.

\section{CONCLUSION}

Sustainability in an Imaginary World, the project and the installation, is an experiment with an unorthodox approach to public engagement with sustainability. This approach, we note above, puts forth two propositions, one about the way sustainability may be interpreted, the other about how it may be communicated. We address them in order below, with an additional reflection on the use of open-endedness as a design feature, which we take as one of the installation's most important design innovations. Our conclusions are preliminary because they 
are based on a single set of pilot workshops that suffered several technical difficulties. At the same time, we believe that even a speculative analysis may produce useful insights, especially when creating experimental media.

\section{Plurality of meanings}

In relation to the first proposition offered here, that rendering explicit the ontological premise of sustainability in deeply held beliefs about the world may lead to the pluralization of sustainability's meanings and the opening up of new agentic paths, we found that the installation was mostly successful. Although technical difficulties made the latter aim challenging (the frequently malfunctioning act of leaf choice was supposed to consummate these new agentic modalities), participants were open to interpret sustainability in ways they did not consider before. And although surveys indicated otherwise (perhaps because of the way the question was worded, asking about changes in meaning instead of openness to other meanings), in postsurvey conversations participants were both reflexive and transformative about their own approach to sustainability. Our efforts, however, should be seen in the context of who participated in the installation, in this case, people with already high levels of involvement in sustainability. This meant that participants were both already conscious of sustainability and therefore more likely to reconsider it, but also more likely to try and fit the experience into their existing interpretations of sustainability, a variation of the confirmation bias, and less likely to be receptive to the installation's meta-interpretive message, that is, that all interpretations are always already premised in deeper ways of being. In this sense, it is important to note that although the installation featured three worlds and gave these worlds equal representation in the three rooms, it embodied a position largely associated with what we call above the literary world. The fact that the installation put forth the possibility of coexisting, equally plausible and equally significant worlds can itself only exist in a world that allows this kind of ontological pluralism.

\section{Experiential resonance}

With regard to the second proposition put forth by the project, that sustainability could be communicated with aesthetic, experiential, playful modalities, although we are quite satisfied with the way the installation functioned as a work of art, we are still concerned about the way it combines theatrical and interactive elements. More specifically, we feel that the way the installation features these elements, along with the way the installation was advertised, may have created or amplified preexisting expectations with participants. This became clear when some participants reported that they expected a more theatrical experience, and were then disappointed when the more dramatic part of the installation transformed into a decision-making experience. Others reported the inverse, expressing their disappointment when their expectations to engage in collective decision making over the kind of complex problem solving they identified with sustainability were frustrated. For these participants, the fact that they were not given more information, additional tasks, and more riddles to solve was disappointing. In postexperience conversations, however, several participants reflected on their disappointment and discovered its roots in the very kind of singular approach to sustainability we aimed to problematize.
Perhaps the more important lesson here is that in creating such complex, multimodal media we need to pay more attention to the relations between participant expectations and the installation's structure. Reflecting back on some of our design decisions, we see that the experience we produced fell in between various "idioms of consumption" leaving participants uncertain as to which instincts or interpretive strategies were "correct" for the encounter. In the installation's remount we intend to manage this uncertainty, whether by resolving it in one direction or the other (more theatrical or more interactive), by creating more explicit behavioral cues for participants, or by adjusting the narrative frames and marketing material we use.

\section{Labyrinthine paths}

We note above that the installation mobilized open-endedness both spatially and hermeneutically. This was based on a homology between our approach to sustainability and the kind of experiential effects we wanted to evoke. Spatially, however, the installation was less labyrinthine than we were initially hoping for. Some sequence of movement had to be built into the experience to avoid chaos, anxiety, and bafflement. With that said, in conversation, most participants expressed their appreciation of the installation's unusual spatial arrangement, and the different types of movement through the installation we discuss above testify to the relative success of this particular strategy. At the hermeneutic level, the results of such openness were mixed. Although many participants enjoyed the freedom to perceive and interpret the installation as they pleased, others expressed their frustrations about not having enough guidance. In remounting the installation, we aim to address this concern not by creating a stronger narrative through line but by pushing the openendedness even further to alleviate participant concerns as to whether they are "getting it right" or "understand" what is going on. Once we create a better match between the physical design, the textual and imagistic elements, we expect the labyrinthine dimension to resonate more consistently through the different layers of the experience.

Although the mainstream of public engagement on sustainability promotes a dynamic by which scientific knowledge about planetary boundaries cascades to policy makers who are called to deliberate and choose among a series of trade-offs, and then to the public who is called to make the necessary "sacrifices" by adopting greener lifestyle choices, our approach foregrounds the malleability of the future as a repository of potentiality. The upshot is that in the pursuit of sustainability we have only ourselves to rely on. And although the absence of some form of transcendental truth to guide us may cause concern for others, we find comfort in knowing that sustainability futures are plural, and that we all have the capacity to imagine and pursue them.

Responses to this article can be read online at: http://www.ecologyandsociety.org/issues/responses. $\mathrm{php} / 9240$

\section{Acknowledgments:}

Sustainability in an Imaginary World was supported by an Insight grant from the Canadian Social Sciences and Humanities Research 
Council (SSHRC). Project collaborators include (in alphabetical order) Junia Anacleto, Roy Bendor, Eric Chad, Emily Cooper, Jeffrey Elrick, Drew Facey, Sid Fels, Robert Gardiner, Joel Grinke, Tim Herron, Elia Kirby, Joey Lesperence, David Maggs, Benton Neufeld, Rachel Peake, Patrick Pennefather, John Robinson, Michael Robinson, Jon Salter, Stephen Sheppard, Obi Vattanawong, Austin Wang, Steve Williams, and Sharon Zimmerman.

\section{LITERATURE CITED}

Bendor, R., J. Anacleto, D. Facey, S. Fels, T. Herron, D. Maggs, R. Peake, J. Robinson, M. Robinson, J. Salter, S. Sheppard, O. Vattanawong, A. Wang, and S. Williams. 2015. Sustainability in an imaginary world. Interactions 22(5):54-57. http://dx.doi. org/10.1145/2801039

Berger, P. L., and T. Luckmann. 1989. The social construction of reality: a treatise in the sociology of knowledge. Anchor Books, New York, New York, USA.

Castree, N., W. M. Adams, J. Barry, D. Brockington, B. Büscher, E. Corbera, D. Demeritt, R. Duffy, U. Felt, K. Neves, P. Newell, L. Pellizzoni, K. Rigby, P Robbins, L. Robin, D. Bird Rose, A. Ross, D. Schlosberg, S. Sörlin, P. West, M. Whitehead, and B. Wynne, B. 2014. Changing the intellectual climate. Nature Climate Change 4: 763-768. http://dx.doi.org/10.1038/nclimate2339

Connelly, S. 2007. Mapping sustainable development as a contested concept. Local Environment: The International Journal of Justice and Sustainability 12(3):259-278. http://dx.doi. org/10.1080/13549830601183289

Dunne, A., and F. Raby. 2001. Design noir: the secret life of electronic objects. August/Birkhäuser, Basel, Switzerland.

Ehrenfeld, J. 2008. Sustainability by design. Yale University Press, New Haven, Connecticut, USA.

Garrard, G., G. Handwerk, and S. Wilke. 2014. Introduction: imagining anew: challenges of representing the Anthropocene. Environmental Humanities 5:149-153. http://dx.doi. org/10.1215/22011919-3615451

Goodman, N. 1978. Ways of worldmaking. Hackett, Indianapolis, Indiana, USA.

Green, L. W., and M. W. Kreuter. 2005. Health program planning: an educational and ecological approach. Fourth edition. McGrawHill, New York, New York, USA.

Hine, D. W., W. J. Phillips, R. Cooksey, J. P. Reser, P. Nunn, A. D. G. Marks, N. M. Loi, and S. E. Watt. 2016. Preaching to different choirs: how to motivate dismissive, uncommitted, and alarmed audiences to adapt to climate change? Global Environmental Change 36:1-11. http://dx.doi.org/10.1016/j. gloenvcha.2015.11.002

Hulme, M. 2009. Why we disagree about climate change: understanding controversy, inaction and opportunity. Cambridge University Press, Cambridge, UK. http://dx.doi.org/10.1017/ $\underline{\mathrm{cbo} 9780511841200}$

Jackson, T. 2005. Motivating sustainable consumption: a review of evidence on consumer behaviour and behavioural change. Report to the Sustainable Development Research Network. University of Surrey, Centre for Environmental Strategy, Guildford, Surrey, UK.

Jacobs, M. 2006. Sustainable development as a contested concept. Pages 21-45 in A. Dobson, editor. Fairness and futurity: essays on environmental sustainability and social justice. Oxford University Press, Oxford, UK. http://dx.doi.org/10.1093/0198294891.003.0002

Krueger, M. W. 2003. Responsive environments. Pages 379-389 in N. Wardrip-Fruin and N. Montfort, editors. The new media reader. MIT Press, Cambridge, Massachusetts, USA.

Latour, B. 2004. Why has critique run out of steam? From matters of fact to matters of concern. Critical Inquiry 30(2):225-248. http://dx.doi.org/10.1086/421123

Lövbrand, E., S. Beck, J. Chilvers, T. Forsyth, J. Hedrén, M. Hulme, R. Lidskog, and E. Vasileiadou. 2015. Who speaks for the future of Earth? How critical social science can extend the conversation on the Anthropocene. Global Environmental Change 32:211-218. http://dx.doi.org/10.1016/j.gloenvcha.2015.03.012

Maggs, D., and J. Robinson. 2016. Recalibrating the Anthropocene: sustainability in an imaginary world. Environmental Philosophy 13(2):175-194. http://dx.doi.org/10.5840/ envirophil201611740

McKenzie-Mohr, D. 2011. Fostering sustainable behavior: an introduction to community-based social marketing. Third edition. New Society, Gabriola Island, British Columbia, Canada.

Meadows, D. H., D. L. Meadows, J. Randers, and W. W. Behrens III. 1972. The limits to growth: a report for the Club of Rome's project on the predicament of mankind. Universe Books, New York, New York, USA. http://dx.doi.org/10.1349/ddlp.1

Miller, T. R. 2013. Constructing sustainability science: emerging perspectives and research trajectories. Sustainability Science 8 (2):279-293. http://dx.doi.org/10.1007/s11625-012-0180-6

Moffat, S. 2014. Resilience and competing temporalities in cities. Building Research \& Information 42(2):202-220. http://dx.doi. org/10.1080/09613218.2014.869894

Rittel, H. W. J., and M. M. Webber. 1973. Dilemmas in a general theory of planning. Policy Sciences 4:155-169. http://dx.doi. org/10.1007/BF01405730

Robinson, J. 2004. Squaring the circle? Some thoughts on the idea of sustainable development. Ecological Economics 48:369-384. http://dx.doi.org/10.1016/j.ecolecon.2003.10.017

Robinson, J., and R. J. Cole. 2015. Theoretical underpinnings of regenerative sustainability. Building Research \& Information 43 (2):133-143. http://dx.doi.org/10.1080/09613218.2014.979082

Rockström, J., and M. Klum. 2015. Big world, small planet: abundance within planetary boundaries. Yale University Press, New Haven, Connecticut, USA.

Rorty, R. 2007. Philosophy as a transitional genre. Pages 3-28 in Philosophy as cultural politics. Cambridge University Press, Cambridge, UK. http://dx.doi.org/10.1017/cbo9780511812835.007

Shove, E. 2010. Beyond the ABC: climate change policy and theories of social change. Environment and Planning $A$ 42:1273-1285. http://dx.doi.org/10.1068/a42282 
Steg, L., and C. Vlek. 2009. Encouraging pro-environmental behaviour: an integrative review and research agenda. Journal of Environmental Psychology 29:309-317. http://dx.doi.org/10.1016/ j.jenvp.2008.10.004

Taylor, C. 2004. Modern social imaginaries. Duke University Press, Durham, North Carolina, USA.

Vervoort, J. M., R. Bendor, A. Kelliher, O. Strik, and A. E. R. Helfgott. 2015. Scenarios and the art of worldmaking. Futures: The Journal of Policy, Planning and Futures Studies 74:62-70. http://dx.doi.org/10.1016/j.futures.2015.08.009

Watson, D., L. A. Clark, and A. Tellegen. 1988. Development and validation of brief measures of positive and negative affect: the PANAS scales. Journal of Personality and Social Psychology 54(6):1063-1070. http://dx.doi.org/10.1037/0022-3514.54.6.1063

Watzlawick, P. 1977. How real is real? Confusion, disinformation, communication. Vintage Books, New York, New York, USA.

Yusoff, K., and J. Gabrys. 2011. Climate change and the imagination. Wiley Interdisciplinary Review: Climate Change 2:516-534. http://dx.doi.org/10.1002/wcc.117 